\title{
JURISPRUDENCIA AMBIENTAL EN LA COMUNIDAD DE MADRID (PRIMER SEMESTRE 2017)
}

\author{
ANTONIO FORTES MARTíN \\ Profesor titular de Derecho Administrativo \\ Universidad Carlos III de Madrid
}

\begin{abstract}
Sumario: 1. Eventual responsabilidad patrimonial ante la prohibición de actividad extractiva en zona perteneciente a parque regional. 2. Efectos ambientales de la limitación de alturas en el modelo urbanístico de Madrid. 3. Alcance de la licencia de funcionamiento en el régimen de actividades clasificadas. 4. Evaluación ambiental caso por caso y aplicación de normativa ambiental ulteriormente derogada. 5. Instalación de huertos ecológicos en zona de especial protección. 6. Principio de proximidad en la renovación de la autorización de sistema integrado de gestión de residuos de envases y envases usados de vidrio.
\end{abstract}

\section{EVENTUAL RESPONSABILIDAD PATRIMONIAL ANTE LA PROHIBICIÓN DE ACTIVIDAD EXTRACTIVA EN ZONA PERTENECIENTE A PARQUE REGIONAL}

La Sentencia del Tribunal Supremo (TS) núm. 2093, de 27 de septiembre de 2016, de la Sala de lo Contencioso-Administrativo resuelve el recurso de casación interpuesto por una mercantil contra la Sentencia del Tribunal Superior de Justicia de Madrid (en adelante, TSJM) núm. 803, de 19 de noviembre de 2014, desestimatoria a su vez de la reclamación de responsabilidad patrimonial presentada por la actora ante la Consejería de Medio Ambiente por los supuestos daños y perjuicios sufridos como consecuencia del acuerdo de prohibición de desarrollo de la actividad extractiva que venía realizando la actora en un área de protección situada en la zona D del Parque Regional del Sureste de Madrid conforme a una autorización de explotación de recursos de la Sección A, grava y arena, otorgada en su día por la Dirección General de Industria, Energía y Minas de la Comunidad de Madrid.

El objeto de la controversia, resuelta en casación por el TS, se centra en la eventual responsabilidad por actos legislativos por el cese de actividad minera, sin reconocimiento de indemnización, impuesto por la Ley 6/1994, de 28 de junio, sobre el Parque Regional en torno a los ejes de los cursos bajos de los 
ríos Manzanares y Jarama. Concretamente, se centra en el momento de producirse los hechos, a partir de lo dispuesto por el artículo 139.3 de la Ley 30/1992, de 26 de noviembre, de Régimen Jurídico de las Administraciones Públicas y del Procedimiento Administrativo Común —hoy día artículo 32.3 de la Ley 40/2015, de 1 de octubre, de Régimen Jurídico del Sector Público-. La Ley 6/1994, de 28 de junio, declaró como Parque Regional los terrenos en torno a los ejes de los cursos bajos de los ríos Manzanares y Jarama, y estableció, además, un régimen jurídico especial que garantizase la ejecución de un plan de ordenación de los recursos naturales y un plan rector de uso y gestión con la finalidad de proteger, conservar y mejorar sus recursos naturales. Pues bien, como consecuencia de la Ley 6/1994 y sus instrumentos de desarrollo (Plan de Ordenación de los Recursos Naturales y Plan Rector de Uso y Gestión), la actividad extractiva de la mercantil recurrente fue reconducida en la parte que resultaba todavía viable, aduciendo la recurrente la causación de importantes pérdidas económicas.

A mayor abundamiento, el artículo 7 de la Ley 6/1994, de 28 de junio, prevé únicamente el reconocimiento de indemnización como consecuencia de las vinculaciones, limitaciones y prohibiciones de los aprovechamientos agrarios establecidas en la propia Ley, y, en virtud de esta, en el Plan Rector de Uso y Gestión y en el Planeamiento Urbanístico, cuando aquellas vinculaciones, limitaciones o prohibiciones no resulten compatibles con la utilización agrícola tradicional y consolidada de los predios. Y lo que cuestiona precisamente la recurrente es la interpretación, por el Tribunal en la instancia, del artículo 7 de la Ley 6/1994, de 28 de julio, de modo que, a su juicio, la Ley 6/1994 debe admitir también, so riesgo de vulnerar el principio de igualdad del artículo 14 $\mathrm{CE}$, la indemnización de cualquier otro uso no agrario que constituya otro tipo de utilización tradicional o consolidada. Porque, para la mercantil demandante, los aprovechamientos mineros, como aquellos de los que ella es titular, constituyen un aprovechamiento natural de los predios que no puede ser prohibido sino por causa de utilidad pública y mediando la correspondiente indemnización.

Con apoyo en doctrina jurisprudencial consolidada del Tribunal Constitucional (Sentencia 170/89, de 19 de octubre, y 149/91, de 4 de julio), el TS determina 
que las limitaciones del derecho de propiedad que introduce la Ley 6/1994 con carácter no indemnizable no vulneran el contenido esencial de los derechos afectados de la mercantil recurrente, puesto que se trata de medidas tendentes a proteger el espacio natural, según la distinta calificación del terreno, y en cumplimiento del mandato que impone el artículo 45 CE. Confirmando, de este modo, el parecer previo del Tribunal en la instancia, el máximo órgano jurisdiccional señala que la medida de prohibición de la actividad de extracción de áridos forma parte de la configuración legal de las facultades del dominio y los derechos existentes sobre dichos terrenos establecidas por la Ley autonómica y no supone, en sí misma, privación de propiedad alguna, ni de bienes ni derechos patrimoniales, sino tan solo el establecimiento de las limitaciones generales y específicas que respecto de los usos y actividades han de dictaminarse como medidas necesarias para la conservación de los espacios naturales a proteger.

En definitiva, a juicio del TS, la prohibición introducida por la Ley 6/1994, de 28 de junio, respecto de la actividad extractiva de áridos representa el legítimo ejercicio de la potestad legislativa autonómica para la delimitación y protección de los espacios naturales objeto de la Ley, de conformidad con la función social de la propiedad en los términos que permite el artículo 33.2 CE. Por lo que, en lógica consecuencia, la ausencia de previsión explícita en la Ley autonómica de indemnización alguna por razón de la prohibición que ha afectado a la recurrente no arroja ningún género de dudas, atendiendo al tenor de su artículo 7, que la limita expresamente a los aprovechamientos agrarios. No cabe equiparar, así pues, el aprovechamiento de recursos mineros de la Sección A con el uso tradicional y consolidado de los terrenos rústicos mediante su aprovechamiento agrario (cuya limitación sí puede ser indemnizable por mandato de la propia Ley 6/1994). La distinta naturaleza del derecho al aprovechamiento minero, a lo que cabe sumar la afectación de los valores naturales de los terrenos en el desarrollo de la actividad extractiva de recursos mineros, constituyen, a juicio del TS, motivos que justifican la proporcionalidad de la decisión del legislador de prohibir determinados usos y delimitar el ámbito del derecho de indemnización a los que son consustanciales al contenido esencial del derecho de propiedad, en los términos que acertadamente ha 
interpretado la sentencia recurrida, por lo que en modo alguno puede advertirse vulneración del principio de igualdad.

Siendo esta prohibición conforme con la configuración constitucional del derecho de propiedad, en la medida en que impone un límite en atención a la función social de los bienes afectados, no existe sino una determinación legal del contenido normal del derecho de propiedad y de la autorización de explotación que le fue otorgada en su día a la recurrente, que esta tiene el deber jurídico de soportar, lo que determina, de forma inexorable, la desestimación del recurso.

\section{EFECTOS AMBIENTALES DE LA LIMITACIÓN DE ALTURAS EN EL MODELO URBANÍSTICO DE MADRID}

La Sentencia del Tribunal Constitucional 170/2016, de 6 de octubre, resuelve el recurso de inconstitucionalidad planteado por cincuenta diputados del Grupo Parlamentario Podemos y sus confluencias contra la disposición adicional de la Ley 4/2015, de 18 de diciembre, de modificación de la Ley 9/2001, de 17 de julio, del Suelo de la Comunidad de Madrid.

En puridad, la sentencia no resuelve una controversia estrictamente ambiental, si bien la traemos a colación en la presente crónica de jurisprudencia ambiental comoquiera que presenta (o puede llegar a presentar) un trasfondo ambiental de gran calado.

En efecto, el Tribunal Constitucional, al decidir la desestimación del recurso de inconstitucionalidad, sin que sea procedente ahora entrar en otro tipo de consideraciones, otorga al mismo tiempo carta de naturaleza al nuevo modelo de desarrollo urbanístico que se propugna, justamente, con la derogación de la limitación de alturas. A juicio del máximo intérprete constitucional, el nuevo modelo urbanístico es expresión de una opción política adoptada al amparo de las competencias autonómicas y no pretende, en absoluto, a diferencia de lo que denunciaban los recurrentes, beneficiar determinadas y concretas actuaciones urbanísticas, como la operación Mahou-Calderón o la operación Chamartín. 
Es más, por lo que aquí realmente nos interesa, el fallo del Tribunal Constitucional esconde, sin manifestarse explícitamente en el pronunciamiento, una consideración ambiental de gran interés por lo que se refiere a la movilidad urbana sostenible en la ciudad. Así, no está de más recordar que la Ley 10/1984, de 30 de mayo, de ordenación territorial de la Comunidad de Madrid, señalaba ya, en su exposición de motivos, una serie de problemas "característicos y graves" referidos a asentamientos dispersos de segunda residencia, implantación incontrolada de instalaciones industriales y clasificaciones como suelo urbanizable de forma indiscriminada que, sin duda, han provocado un importante impacto en los desplazamientos motorizados hasta nuestros días. Buena prueba de ello lo constituye, más de dos décadas después, la exposición de motivos del, hoy día derogado, Real Decreto Legislativo 2/2008, de 20 de junio, por el que se aprueba el texto refundido de la Ley de Suelo. En ella -y con posterior desarrollo en el artículo 2 de la propia Ley- se enfatiza que el urbanismo debe responder a los requerimientos de un desarrollo sostenible, minimizando el impacto de los crecimientos y apostando por la regeneración de la ciudad existente. Para afirmar acto seguido (apartado II) que "la Unión Europea insiste claramente en ello, por ejemplo en la Estrategia Territorial Europea o en la más reciente Comunicación de la Comisión sobre una Estrategia Temática para el Medio Ambiente Urbano, para lo que propone un modelo de ciudad compacta y advierte de los graves inconvenientes de la urbanización dispersa o desordenada: impacto ambiental, segregación social e ineficiencia económica por los elevados costes energéticos, de construcción y mantenimiento de infraestructuras y de prestación de los servicios públicos".

Justo la misma idea sobre la que el propio legislador autonómico insiste en 1984, comoquiera que el "dimensionado y localizado de los nuevos desarrollos se han formulado y se siguen formulando desde una óptica puramente coyuntural y localista", lo que ha determinado la ausencia completa de consideración hacia la puesta a disposición "de unos accesos garantizados en tiempo y coste adecuado".

Poco se ha avanzado desde entonces, puesto que la Ley 4/2015, de 18 de diciembre, de modificación de la Ley 9/2001, de 17 de julio, del Suelo de la 
Comunidad de Madrid, vuelve a incidir sobre este particular. Así, la modificación de la Ley madrileña del suelo —con derogación del apartado 8 del artículo 39- tiene lugar por la limitación de alturas (tres plantas más ático) que incorporaba dicho precepto, que fue introducido por el artículo 13 de la Ley 3/2007, de 26 de julio, de medidas urgentes de modernización del Gobierno y la Administración de Madrid, cuyo tenor disponía:

No podrá edificarse con una altura superior a tres plantas más ático, incluida la baja, plantas retranqueadas y semisótanos que sobresalgan más de un metro, de manera que la edificación resultante no exceda de dichas tres plantas más ático en todos y cada uno de los puntos del terreno, sin perjuicio de las demás limitaciones que sean aplicables.

Dicha limitación podía, no obstante, ser excepcionada por los ayuntamientos a la hora de permitir la construcción de edificios singulares con una altura superior si concurrían circunstancias especiales debidamente motivadas. Una limitación de alturas, como constata muy gráficamente el legislador autonómico en el preámbulo de la Ley $4 / 2015$, de 18 de diciembre, que ha provocado "un caos urbanístico [...] dentro de un mar de sentencias judiciales y paralizaciones de planeamientos de desarrollo que impiden la evolución de nuestras ciudades". Escenario que se hace preciso corregir, ya que el resultado último de la aplicación de dicha limitación de alturas no ha sido otro que el esparcimiento de las ciudades "cual mancha de aceite, generando graves problemas en materia de infraestructuras, movilidad y transporte y por ende problemas medioambientales, debido a la utilización 'obligatoria' del vehículo privado, quedando grandes zonas de la región sin comunicación por servicios públicos y generando una deuda contra estos nuevos desarrollos en materia de dotaciones y equipamientos públicos de primera necesidad".

Sin duda, así pues, la decisión del Tribunal Constitucional, que, de forma indirecta, legitima el nuevo modelo de desarrollo urbanístico que se propugna con la derogación de la limitación de alturas, está llamada a contribuir a una mejora ambiental de los desplazamientos urbanos que solo el tiempo permitirá constatar realmente. 


\section{ALCANCE DE LA LICENCIA DE FUNCIONAMIENTO EN EL RÉGIMEN DE ACTIVIDADES CLASIFICADAS}

La Sentencia del TSJM núm. 4, de 18 de enero de 2017, resuelve el recurso de apelación interpuesto por el Ayuntamiento de Madrid contra la Sentencia del Juzgado de lo Contencioso-Administrativo núm. 15 de Madrid por la que se estimó el recurso de la demandante relativo a la solicitud y otorgamiento de licencia de actividades clasificadas para la actividad de almacén de envases vacíos.

El pronunciamiento que ahora es objeto de nuestra atención evidencia, todavía, una realidad procedimental y ambiental que debiera estar completamente clara y definida. No solo por lo que se refiere a los particulares, sino también a la propia Administración. Y con ello nos referimos a la problemática que genera una resolución municipal de concesión de licencia de instalación, apertura y funcionamiento.

En efecto, el régimen de actividades clasificadas dispuesto por el viejo Decreto 2414/61, de 30 de noviembre, estableció ya en su momento una clara secuencia de la que el TSJM se hace eco para resolver el recurso en su instancia. Así, una vez otorgada la licencia de instalación (o actividad), esta misma no permite sin más el comienzo del ejercicio de la actividad autorizada, sino que se requiere la necesaria y previa visita de comprobación técnica, que dará lugar, en su caso, a la licencia de apertura (o funcionamiento) y que tiene como condición para su otorgamiento que se hayan adoptado las medidas correctoras que hayan podido determinarse.

Pues bien, en el concreto caso resuelto en apelación por el TSJM, pese al parecer del Juzgado de lo Contencioso-Administrativo, no hay constancia en los autos de la concesión de la licencia de funcionamiento al no existir evidencia alguna de la realización de la visita de inspección técnica y, por tanto, de resultas de esta, de la autorización de la licencia de funcionamiento. La constancia de la concesión de la licencia viene referida únicamente a la de la licencia de instalación, sin que figure licencia de funcionamiento alguna, por lo que la actividad se puso en marcha sin adoptarse las medidas correctoras exigibles. 
A mayor abundamiento, y retomando una sólida doctrina jurisprudencial del TS, ni el transcurso del tiempo, ni el pago de tributos, tasas o impuestos ni la tolerancia municipal pueden entrañar acto tácito de otorgamiento de licencia, debiéndose conceptuar, por el contrario, la actividad ejercida por la actora en la instancia sin licencia y, por ende, como clandestina e irregular, sin que se pueda legitimar por el transcurso del tiempo, por lo que la autoridad municipal puede acordar su paralización o cese en cualquier momento. No se ha producido en ningún momento adquisición de derecho alguno, ni puede entenderse que la actividad municipal se aparte de lo establecido en el ordenamiento jurídico o del principio de buena fe o tenga carácter discrecional, puesto que la actividad, aunque se haya otorgado la licencia de actividad, sigue siendo clandestina si no se ha solicitado y concedido en algún momento la licencia de funcionamiento.

\section{EVALUACIÓN AMBIENTAL CASO POR CASO Y APLICACIÓN DE NORMATIVA AMBIENTAL ULTERIORMENTE DEROGADA}

La Sentencia núm. 46, de 25 de enero de 2017, de la Sala de lo ContenciosoAdministrativo del TSJM resuelve el recurso de apelación interpuesto contra la Sentencia de 18 de mayo de 2016 del Juzgado de lo ContenciosoAdministrativo núm. 33 de Madrid que resolvió, a su vez, el recurso contra el Decreto de la Alcaldía del Ayuntamiento de Cercedilla por el que se ordena la suspensión inmediata del ejercicio de actividad por encontrarse sometida a procedimiento de evaluación ambiental caso por caso.

La recurrente estima que han quedado derogadas las disposiciones legales sobre las que el Ayuntamiento demandado instruyó el expediente administrativo de inspección por el que se acreditó el ejercicio de actividad sin ningún tipo de licencia, puesto que el 12 de diciembre de 2013 entró en vigor la Ley $21 / 2013$, de 9 de diciembre, de evaluación ambiental, con desplazamiento, por derogación ulterior, de la Ley 2/2002, de 19 de junio, de evaluación ambiental de la Comunidad de Madrid.

Sin perjuicio de que el motivo esgrimido por la recurrente no puede ser acogido por haber sido aducido ex novo en la segunda instancia y no alegado en el 
escrito de demanda, a juicio del TSJM la Ley 2/2002, de 19 de junio, no se encontraba derogada por la Ley 4/2014, de 22 de diciembre, de Medidas Fiscales y Administrativas, en el momento de constatar el Ayuntamiento demandado el ejercicio de la actividad sin contar con licencia de apertura y sin sujetarse a procedimiento ambiental alguno. La propia Ley 21/2013, de 9 de diciembre, señala en su disposición adicional undécima que las comunidades autónomas que dispongan de legislación propia en materia de evaluación ambiental deberán adaptarse a lo dispuesto en esa Ley en el plazo de un año desde su entrada en vigor.

Es así como se descubre que el demandante ejercía su actividad sin cumplir con lo dispuesto en el artículo 5.3 de la Ley 2/2002, conforme al cual serán objeto de estudio caso por caso los proyectos y las actividades recogidos en el anexo cuarto de la Ley, limitándose el Ayuntamiento demandado a suspender el ejercicio de la actividad en los términos previstos por el artículo 55.1 (suspensión de la ejecución de planes, programas, proyectos o actividades "que hayan empezado a ejecutarse sin contar con alguno de los informes, declaraciones o autorizaciones ambientales cuando éstas sean preceptivas").

\section{INSTALACIÓN DE HUERTOS ECOLÓGICOS EN ZONA DE ESPECIAL PROTECCIÓN}

La Sentencia núm. 91, de 8 de febrero de 2017, de la Sala de lo ContenciosoAdministrativo del TSJM resuelve el recurso contencioso-administrativo interpuesto contra la Resolución del director general de Urbanismo y Estrategia Territorial de la Consejería de Medio Ambiente de la Comunidad de Madrid por la que se denegaba una calificación urbanística solicitada para la instalación de 87 huertos ecológicos de $50 \mathrm{~m}^{2}$ cada uno.

Para la denegación de la calificación urbanística resultan fundamentales dos informes desfavorables del Área de Conservación de Montes de la Dirección General del Medio Ambiente que señalan que la parcela destinada a albergar los huertos ecológicos se encuentra en la zona $B$-de protección y mantenimiento de usos tradicionales- del espacio protegido red Natura 2000 "Cuencas de los ríos Jarama y Henares" conforme a su Plan de Gestión 
(aprobado por Decreto 179/2011, de 3 de noviembre) y no concurren, tampoco, los requisitos exigidos en el artículo 29 de la Ley 9/2001, de 17 de julio, del Suelo de la Comunidad de Madrid. A mayor abundamiento, a juicio de la Comunidad de Madrid, el suelo donde se pretende ubicar la instalación tiene la calificación de no urbanizable de protección faunística, además de tratarse de una zona especial de conservación y una zona de especial protección para las aves. De modo que, de autorizarse su implantación, quedarían afectadas las actividades y superficies agrarias (de cereal secano) que han dado lugar, precisamente, a la declaración del espacio como zona especial de conservación, por lo que resulta necesario conservar la máxima superficie de vegetación natural y de cultivos y limitar, en última instancia, nuevas intrusiones artificiales para evitar la pérdida de hábitats naturales, estepas cerealistas de origen agrario y especies, y mantener los umbrales de tranquilidad necesarios para la preservación de las especies faunísticas.

La Sala del TSJM no cuestiona que los usos, aprovechamientos y actividades pretendidos por el proyecto se pueden clasificar en el Plan de Gestión como "valorables" dentro de la zona B (la construcción de edificaciones ligadas a las explotaciones agrarias, así como el accesorio vivienda, la implantación de explotaciones agrícolas intensivas, los invernaderos y los cultivos, entre otros). Esto significa que se trata de proyectos que no son directamente compatibles o incompatibles y que la Consejería de Medio Ambiente los puede autorizar "tras un análisis de sus posibles afecciones y alternativas". Ahora bien, no puede desconocerse que entre los principios que rigen el Plan de Gestión se encuentra, de forma indubitada, la prevalencia de la protección ambiental sobre la ordenación territorial y urbanística, "lo que implica una clara preponderancia de los valores ambientales sobre los urbanísticos, con el alcance restrictivo que ello supone para las expectativas de expansión de los núcleos urbanos incluidos en su ámbito de aplicación".

Y no es casual la inserción del proyecto entre los pretendidos usos "valorables", comoquiera que el otorgamiento de las calificaciones urbanísticas implica el ejercicio de un cierto margen de discrecionalidad, dado que nos encontramos, a juicio del TSJM, ante "una facultad extraordinaria respecto de las que conforman el derecho de propiedad del suelo de una finca que se encuentre en 
suelo no urbanizable que habilita para la implantación de un uso que no es el ordinario". Es así como el control jurisdiccional no puede ser pleno al no tratarse de una potestad reglada, lo que no quiere decir tampoco que no haya control judicial, el cual, necesariamente, deberá tender a comprobar si el criterio se ha adoptado dentro de unos márgenes de razonabilidad y proporcionalidad.

Para la Sala del TSJM, la denegación de la calificación urbanística no ha sido irrazonable o desproporcionada y la valoración que ha hecho la Administración autonómica se ajusta a los principios que rigen el Plan de Gestión de la zona especial de conservación.

\section{PRINCIPIO DE PROXIMIDAD EN LA RENOVACIÓN DE LA} AUTORIZACIÓN DE SISTEMA INTEGRADO DE GESTIÓN DE RESIDUOS DE ENVASES Y ENVASES USADOS DE VIDRIO

La Sentencia del TS núm. 216, de 9 de febrero de 2017, resuelve el recurso de casación interpuesto por Ecovidrio contra la Sentencia del TSJM de 12 de noviembre de 2015 que resolvía, a su vez, el recurso contenciosoadministrativo contra la Orden 554/2014, de 24 de marzo, de la Consejería de Medio Ambiente y Ordenación del Territorio de la Comunidad de Madrid por la que se renueva la autorización del sistema integrado de gestión de residuos de envases y envases usados de vidrio.

En concreto, son varios puntos los conflictivos en la decisión de la Comunidad de Madrid de renovar la autorización, siempre a juicio de Ecovidrio. El más destacado es el que se refiere a la gestión de los residuos de envases usados en la Comunidad de Madrid en función de los principios de proximidad y suficiencia. En este sentido, la valorización de los residuos de envases y envases usados generados por la Comunidad de Madrid se llevará a cabo, siempre que sea posible, en instalaciones ubicadas en la propia Comunidad Autónoma.

La Sala en instancia no apreció vulneración de los artículos 9 y 25 de la Ley 22/2011, de 28 de julio, de residuos y suelos contaminados, ni de la normativa europea. Pero la recurrente considera que la condición impuesta pretende 
realizar una aplicación del principio de proximidad en los traslados de residuos contraria a lo previsto tanto en la normativa estatal interna como en la normativa europea y en la jurisprudencia del Tribunal Supremo y del Tribunal de Justicia de la Unión Europea. Y ello porque, según el parecer siempre de la recurrente en casación, la Comunidad de Madrid pretende aplicar los principios de proximidad y autosuficiencia a supuestos no contemplados ni en la Ley estatal ni en la normativa europea, además de permitir la posibilidad de oponerse a traslados de residuos hacia otras comunidades autónomas por causas ajenas a las previstas en la citada normativa.

El máximo órgano jurisdiccional, a la hora de resolver este punto controvertido, analiza el alcance de los principios de autosuficiencia y proximidad sobre la base de que los residuos destinados a su eliminación y los residuos domésticos mezclados deben necesariamente eliminarse o valorizarse en el territorio de la Comunidad Autónoma donde se generen, siempre que existan instalaciones habilitadas para ello. $Y$, de no ser posible, en aquellas instalaciones existentes en otras comunidades autónomas cercanas al lugar de generación de los residuos. De forma que todos los demás flujos de residuos, como los aquí considerados, pueden ser eliminados o tratados en una comunidad autónoma distinta a la de su procedencia, siempre que queden sujetos al régimen de intervención administrativa previsto en la ley. Es así como, a juicio del TS, teniendo en cuenta que la Ley 22/2011, de 28 de julio, de residuos y suelos contaminados, restringe la facultad de las comunidades autónomas para poner limitaciones al libre traslado de residuos entre ellas únicamente para los residuos destinados a la eliminación, con independencia de su naturaleza, y para los residuos domésticos mezclados (los no provenientes de la recogida selectiva) destinados a la valorización, el principio de proximidad debe compatibilizarse en determinados casos con la prioridad de la valorización como vía de gestión, por lo que, para fomentar esta última, la normativa vigente establece que el principio de proximidad no se aplica a los residuos destinados a valorización, distintos de los residuos mezclados procedentes de los hogares.

A mayor abundamiento y tras apoyarse en un pronunciamiento del Tribunal de Justicia de la UE y en jurisprudencia precedente de la propia Sala de lo 
Contencioso-Administrativo del TS, el máximo órgano jurisdiccional considera que no cabe la posibilidad de extender la virtualidad del principio de proximidad más allá de los supuestos en que dicho principio está previsto legalmente, puesto que ello contrariaría los principios de libre circulación, libertad de empresa y libre competencia que exige el acervo comunitario. Es por ello por lo que finalmente se estima el recurso de casación de Ecovidrio y, en lógica consecuencia, se casa y anula la Sentencia del TSJM de 12 de noviembre de 2015, y se estima el recurso contencioso-administrativo contra la Orden 554/2014, de 24 de marzo. 